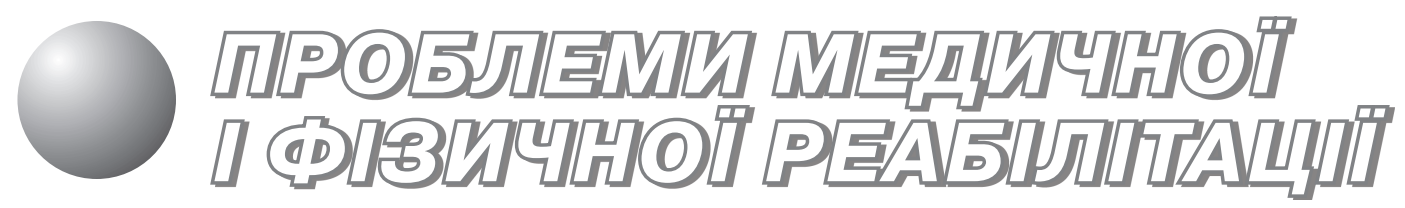

\section{Роль і місце лікувальної ходьби у системі фізичної реабілітації}

\author{
УдК 615.825.4:796.012.41 \\ О. Г. Юшковська
}

Одеський національний медичний університет, Одеса, Україна

\begin{abstract}
Pesюме. Мета. У статті наведено сучасний погляд на можливості лікувальної ходьби самостійного засобу фізичної реабілітації, що ґрунтується на розумінні основних біомеханічних уявлень про ходьбу як основну локомоцію, яка робить людину незалежною від сторонньої допомоги. Сформульовано нові підходи до розуміння засад і принципів локомоторного патерну ходьби. Особливу увагу приділено локомоторному тренуванню хворих як сучасній реабілітаційній стратегії, що забезпечує якісне відновлення функціональних можливостей хворих. Методи. Наведено результати власних досліджень із використанням крокових тестів, а саме тесту з шестихвилинною ходьбою. Результати. Отримані дані дозволяють використовувати крокові тести як самостійний предиктор ефективності лікувальних i реабілітаційних програм кардіологічних хворих у зв'язку з високою ефективністю, невисокою вартістю, можливістю інтегральної оцінки психосоматичного стану. При цьому оцінюється саме той вид навантаження, який використовується в повсякденному житті хворих, тобто ходьба, тестування не потребує високовартісного обладнання і може проводитися в будь-якій лікувальній або реабілітаційній установі. 3 допомогою результатів проведеного тесту можна оцінити функціональні можливості хворих, ефективність застосування лікувальних заходів, а також підібрати інтенсивність навантаження у пацієнтів із захворюваннями серцево-судинної, дихальної систем та опорно-рухового апарату. Висновки. Лікувальна дозована ходьба - це самостійний засіб, що посідає одне з важливих місць у системі фізичної реабілітації, який може бути застосований як на стаціонарному, так і на санаторному етапі, а також активно самостійно широким колом пацієнтів з різноманітними захворюваннями.
\end{abstract}

Ключові слова: лікувальна ходьба, фізична реабілітація, локомоторне тренування, тест із шестихвилинною ходьбою.

Резюме. Цель. В статье представлены современные взгляды на возможности лечебной ходьбы - самостоятельного средства физической реабилитации, которые основываются на понимании основных биомеханических представлений о ходьбе как основной локомоции, делающей человека независимым от посторонней помощи. Приведены новые подходы к пониманию принципов локомоторного паттерна ходьбы. Особое внимание уделено локомоторной тренировке больных как современной реабилитационной стратегии, обеспечивающей качественное восстановление функциональных возможностей больных. Методы. Приведены результаты собственных исследований с использованием шаговых тестов, в частности теста с шестиминутной ходьбой. Результаты. Полученные данные позволяют использовать шаговые тесты в качестве самостоятельного предиктора эффективности лечебных и реабилитационных программ кардиологических больных в связи с высокой эффективностью, низкой стоимостью, возможностью интегральной оценки психосоматического состояния. При этом оценивается именно тот вид нагрузки, который используется в повседневной жизни больных, то есть ходьба, тестирование не требует дорогостоящего оборудования и может проводиться в любом лечебном или реабилитационном учреждении. Руководствуясь результатами проведенного теста, можно оценить функциональные возможности больных, эффективность примененных лечебных мероприятий, а также подбирать интенсивность нагрузки у пациентов с заболеваниями 
сердечно-сосудистой, дыхательной систем и опорно-двигательного аппарата. Выводы. Лечебная дозированная ходьба - это самостоятельное средство, занимающее одно из важных мест в системе физической реабилитации, которое может быть применено как на стационарном, так и на санаторном этапе, а также активно самостоятельно широким кругом пациентов с различными заболеваниями. Ключевые слова: лечебная ходьба, физическая реабилитация, локомоторная тренировка, тест с шестиминутной ходьбой.

Abstract. Objective. The article presents current views on the possibilities of walking training as an independent means of physical rehabilitation, based on understanding the basic biomechanical concepts of walking as the main locomotion, which makes a person independent of outside help. New approaches to understanding the principles of the locomotor pattern of walking are presented. Particular attention is given to locomotor training of patients as a modern rehabilitation strategy, ensuring qualitative recovery of the functionality of patients. Methods. The results of own studies using the step tests, in particular the six-minute walking test, are presented. Results. The findings allow to use step tests as an independent predictor of the effectiveness of treatment and rehabilitation programs of cardiac patients due to the high efficiency, low cost, possibility of an integrated estimation of psychosomatic condition. Thus, it is estimated that type of load, which is used in the daily life of patients, i.e. walking does not require expensive equipment and can be performed at any medical or rehabilitation facility. Based on the results of this test, it is possible to evaluate the functionality of the patients, the effectiveness of therapeutic interventions, as well as to select the load intensity for patients with diseases of cardiovascular, respiratory and musculoskeletal system. Conclusions. Therapeutic dosed walking is an independent important means in the system of physical rehabilitation, which can be used as stationary and at a sanatorium stage, as well as by a wide range of patients with different diseases independently.

Keywords: walking training, physical rehabilitation, locomotor training, 6-min walking test.

Постановка проблеми. На сучасному етапі історичного розвитку незалежності країни, коли значущість фрізичної реабілітації (ФР) хворих після різноманітних травм і повернення до повноцінного життя виходять на перший план, існує необхідність пошуку та застосування саме таких засобів і технологій, які б дозволили у найкоротші терміни зробити пересування пацієнтів самостійним. Однією з найважливіших у цьому сенсі локомоцій $\epsilon$ саме ходьба. Локомоція (від лат. locus - місце та motio - pyx) - це переміщення тіла 3 одного місця простору в інше. Зусилля, що докладаються під час ходьби, мають подолати силу тяжіння, опір навколишнього середовища та силу інерції тіла. Ходьба людини - це пересування на двох ногах, для якого характерні дві фрази - опори і переносу, котрі мають чергуватися наступним чином: фраза опори для лівої нижньої кінцівки, фраза переносу, двоопірний період, фраза переносу, фаза опори для правої нижньої кінцівки - з циклічним повторенням цього локомоторного патерну. Ходьба людини характеризується певним способом пересування по поверхні, який відрізняється для кожного індивідууму за розподілом у часі циклічних рухів кінцівок, тривалістю опорної фрази і послідовністю переміщення опорних кінцівок. Важливою особливістю $€$ необхідність підтримувати рівновагу. Центр маси тіла під час ходьби здійснює рухи у 3D-просторі. Саме неможливість ходьби та фрормування патологічного стереотипу ходьби, що виникають у великої кількості паці$\epsilon н т і в$, які перенесли гострі порушення мозкового кровообігу, травми та захворювання спинного та головного мозку, нижніх кінцівок тощо, спонукають фахівців до пошуку нових і вдосконалення наявних технологій фрізичної реабілітації, спрямованих на відновлення локомоцій.

Аналіз останніх досліджень i публікацій. Ходьба - найбільш доступний і поширений вид фрізичних вправ, що широко застосовується під час лікування переважної більшості захворювань і травм на всіх етапах реабілітації [3]. Вона спрямована на активізацію режиму хворого i повноцінне використання сприятливих умов зовнішнього середовища. Ходьба сприяє оздоровленню, стимулює процеси кровообігу, дихання, обміну речовин, зміцнює переважно м'язи ніг $\mathrm{i}$ таза, але залучає до роботи м'язи всього тіла. Ритмічні чергування напруження і розслаблення м'язів під час ходьби створюють сприятливі умови для заспокоєння організму, водночас ходьба у швидкому темпі дає значне фрізичне навантаження, тренуючи і розвиваючи адаптаційні механізми одужуючого. Фізичне навантаження при ходьбі легко піддається дозуванню і залежить від відстані та рельєфру маршруту, часу та темпу проходження дистанції, кількості інтервалів для відпочинку та їх тривалості. Ходити можна по спеціально розкресленій «слідовій» доріжці, по нерівній поверхні та ін. Ходьбу можна виконувати з розвантаженням за допомогою ціпка та милиць, спеціальних апаратів - ходунків, манежу тощо.

Відповідно до методологічних принципів ФР, лікувальна дозована ходьба - це не лише один 
із різновидів прикладних вправ, а також самостійна форма ФР наряду з лікувальною гімнастикою, ранковою гігієнічною гімнастикою та тренувально-оздоровчими заходами. На сьогодні добре розроблено та стандартизовано методику використання ходьби з лікувальною метою. Вона може застосовуватися як спеціальна вправа, так і для загального розвитку, оздоровлення, бути засобом розвантаження і поступового тренування організму до наростаючих фрізичних навантажень, розвиваючи адаптаційні механізми одужуючого. Ходьба може використовуватися 3 метою відновлення працездатності та стереотипу ходьби, поліпшення рухомості суглобів (при захворюваннях і травмах опорно-рухового апарату та нервової системи) та зміцнення м'язів нижніх кінцівок, для фоорування компенсації у хворого зі стійкими порушеннями механізму ходьби (при ампутаціях, млявих і спастичних парезах, атаксії, паралітичних та інших десормаціях), а також 3 метою активізації вегетативних функцій (кровообігу, дихання, обміну речовин) і відновлення адаптації до навантажень різної інтенсивності. Ходьба широко використовується як самостійна форма ФР при різних захворюваннях, а також як складова частина процедури лікувальної гімнастики.

У ФР використовують такі види ходьби: лікуВальна ходьба рівною місиеВістю; коригуюча $x о \partial ь б a$, що спрямована на усунення порушень, навчання й удосконалення правильної методики ходьби; теренкур - дозовані сходження, які застосовують здебільшого в умовах санаторію з використанням підйому переважно під кутом 5-15; прогулянки, пішохідні екскурсії та ближній туризм, що мають на меті відновлення загальної адаптації хворих до виробничо-побутових умов. Загальний об'єм добового навантаження має становити близько 10000 кроків, для контролю цього рекомендуємо користуватися крокомірами та фрітнес-трекерами. Прогулянки проводять у темпі 2-3 км-год ${ }^{-1}$. Маршрут пішохідної екскурсії - до 15 км за день.

Окремо варто згадати досить новий у фрізичній реабілітації різновид лікувальної ходьби - скандинаљську ходьбу з палицями (північна ходьба, нордична ходьба, фрінська ходьба). Це піші подорожі, під час яких спираються на спеціальні палиці, вигляд яких віддалено нагадує лижні [1].

За темпом проходження дистанції розрізняють такі види ходьби:

- повільна $-60-80$ крок. Хв $^{-1}$ або $3-3,5$ км $\times$ $\times$ год $^{-1}$;

- середня - 80-100 крок." хв ${ }^{-1}$ або 3,5-4 км $\times$ $\times$ год $^{-1}$
- швидка - 100-120 крок."хв ${ }^{-1} а$ або 4-5 км × $\times$ год $^{-1}$;

- дуже швидка - 120 крок. :хв ${ }^{-1}$ і більше або 5 км-год ${ }^{-1}$ і більше.

Результати власних досліджень. У багаторічних дослідженнях ми приділяємо значну увагу застосуванню лікувальної дозованої ходьби як провідному засобу реабілітації на санаторному етапі хворих на ішемічну хворобу серця [5]. Також у дослідженнях ми досконало вивчили можливість використання тестів із ходьбою, так званих «крокових тестів» [6]. Отримані дані дозволяють використовувати їх як самостійний предиктор ефективності лікувальних і реабілітаційних програм кардіологічних хворих у зв'язку 3 їх високою ефективністю, низькою вартістю, можливістю інтегральної оцінки психосоматичного стану. Крокові тести дозволяють оцінити рівень повсякденної активності хворих, оскільки передбачають використання навантаження на субмаксимальному рівні [7, 9, 11]. При цьому оцінюється саме той вид навантаження, який використовується в повсякденному житті хворих, тобто ходьба, тестування не потребує високовартісного обладнання і може проводитися в будь-якій лікувальній або реабілітаційній установі. Існують різні види крокових тестів, проте найбільшого поширення набув тест із шестихвилинною ходьбою. Це максимально фрізіологічна, проста у виконанні і безпечна навантажувальна проба.

Ми проводили тест із шестихвилинною ходьбою відповідно до стандартного протоколу $[6,7]$. Пацієнти були проінструктовані про мету тесту. Їм пропонували ходити по виміряному коридору у власному темпі, прагнучи пройти максимальну відстань протягом 6 хв. При цьому пацієнтам дозволяли зупинятися і відпочивати під час тесту, однак вони повинні були відновлювати ходьбу, коли визнають це можливим. Під час ходьби дозволялося підбадьорювати пацієнтів фрразами: «Все йде добре», «Продовжуйте в тому ж темпі». Перед початком і наприкінці тесту оцінювали пульс та артеріальний тиск. Пацієнти припиняли ходьбу у разі виникнення таких симптомів: виражена задишка, біль у грудній клітці, запаморочення, біль у ногах.

Тест було розроблено на основі проби, що оцінює фрізичну працездатність здорових осіб, і $\epsilon$ субмаксимальним, інформативним і чутливим стрес-тестом низької потужності. Толерантність до фрізичного навантаження, зареєстрована під час виконання стандартної велоергометрії та тредмілергометрії, добре корелює 3 результатами тесту 3 шестихвилинною ходьбою. У 
клінічній практиці цей тест використовують також для об'єктивізації функціонального стану та контролю лікування хронічної серцевої недостатності. Керуючись результатами проведеного тесту, можна вірогідно оцінювати функціональні можливості хворих, ефективність застосованих лікувальних заходів, а також проводити підбір інтенсивності навантаження у пацієнтів із захворюваннями серцево-судинної, дихальної систем та опорно-рухового апарату. Так, відповідно до класифрікації серцевої недостатності, прийнятої IV Національним конгресом кардіологів України (2002), I фрункціональному класу (ФК) серцевої недостатності відповідає пройдена за 6 хв дистанція 426-550 м, II ФК - від 301 до 425 м, III ФК - 151-300 м, IV ФК серцевої недостатності - менше 150 м.

У контексті можливості відновлення рухів важливими $є$ сучасні уявлення про теорію центрального спінального генератора циклічних локомоцій (Central Pattern Generators), згідно з якою в спинному мозку існує ланцюг нейронів, що виконує фрункції генератора крокування [12]. Ця локомоторна програма ходьби активізується під дією сенсорної аферентації від шкірних і суглобово-м'язових рецепторів під час опори на стопи і від м'язових і сухожилкових рецепторів стегна. Якщо розглядати біомеханіку ходьби з позицій фрізіології рухів, стереотип ходьби базується на принципі реципрокної іннервації м'язівантагоністів (від лат. reciprocus - зворотний, взаємний). Цей принцип працює таким чином: скорочення згинача призводить до зниження тонусу розгинача на тій же стороні, а $з$ протилежного боку може спричинити підвищення тонусу розгинача. Саме таку послідовність скорочення м'язів нижніх кінцівок необхідно відтворювати з метою відновлення фрізіологічного стереотипу крокування, тому що ходьба - це умовнорефлекторна локомоція. Підтвердженням цьому $\epsilon$ рефлекс опори й автоматична ходьба новонароджених, що існують до 1-1,5 місяця життя.

Здатність структур спинного мозку до «навчання» та відновлення була вивчена на дослідах зі спінальними (децереброваними) тваринами, що отримали назву «spinal cat» [9]. Було доведено, що спінальні кішки, які регулярно тренувалися на тредмілі, збільшили максимальну швидкість ходьби у 8 разів. Це послугувало вагомим аргументом на користь застосування лікувальної ходьби у хворих із травмами та пошкодженнями спинного мозку.

Саме ці дослідження поклали початок новому напрямку у фрізичній реабілітації та відновленні ходьби - локомоторному тренуванню. Воно ґрунтується на активізації та тренуванні інтернейронних структур спинного мозку, що забезпечують координовану локомоторну активність, включаючи реципрокну активність згиначів і розгиначів ніг і тулуба, що сприяє відновленню функції не окремих м'язів, а локомоторних можливостей пацієнта в цілому. Також невід'ємним компонентом локомоторного тренування $€$ система розвантаження маси тіла (body weight support), яка забезпечує зниження навантаження на кінцівки, що полегшує ходьбу пацієнтів з надлишковою масою тіла, які не можуть ходити у звичайних умовах [2].

Локомоторне тренування $\epsilon$ реабілітаційною стратегією, розробленою для відновлення ходьби за допомогою симуляції ходьби [4, 13, 14]. Основна мета іï полягає в тому, щоб викликати сенсорні сигнали інтернейронних структур спинного мозку з пропріорецепторів стоп і м'язів нижніх кінцівок. Таке тренування можна проводити за участі спеціально підготовлених методистів або за допомогою роботизованих пристроїв, що симулюють ходьбу (екзоскелети, рухливі опори для стоп). Локомоторне тренування передбачає максимально можливе навантаження на ноги, оптимізацію сенсорних сигналів з перифрерії, максимальне відновлення при мінімальній компенсації. Таке тренування можна проводити з хворими, що перебувають на ліжковому режимі внаслідок різноманітних захворювань і травм. Існують моделі столів-вертикалізаторів з інтегрованим роботизованим ортопедичним пристроєм, що дозволяє проводити лікування шляхом стимуляції опорного навантаження на стопи саме для таких хворих, починаючи з перших днів захворювання, що значно підвищує шанси на відновлення мобільності.

Висновки. Лікувальна дозована ходьба - це не лише різновид прикладної вправи, це самостійний засіб, що посідає одне з важливих місць у системі ФР, може бути застосований як на стаціонарному, так і на санаторному етапі, а також активно самостійно широким колом пацієнтів 3 різноманітними захворюваннями. Цей засіб має низку переваг, а саме: легкість у дозуванні та контролі реакції, природність і значущість у соціальній адаптації. Відновлення ходьби за допомогою локомоторного тренування - це найбільш перспективний метод функціональної реабілітації, спрямований на відновлення загальної локомоції ходіння, а не лише окремих м'язів. Він базується на тренуванні інтернейронного апарату спинного мозку, який забезпечує координовану локомоторну активність, що відтворюється спінальним генератором крокування. 


\section{Література}

1. ЛікуВальна дозована нордична ходьба як нова сучасна форма ЛФК у санаторно-курортних умовах : метод. рек. / уклад.: О. А. Владіміров, Н. І. Владімірова, В. В. Єжов [та ін.]. - К., 2011. - 28 с.

2. РумянцеВа Н. А. Комплексная оценка патологического паттерна ходьбы и реабилитационных программ ее восстановления у больных в остром периоде церебрального инсульта : дисс. ... канд. мед. наук : 14.01.11 / Н. А. Румянцева. - М., 2010. - 128 с.

3. Соколовський В. С. Лікувальна фрізична культура : підручник / В. С. Соколовський, Н. О. Романова, О. Г. Юшковська. - Одеса : Одес. держ. мед. ун-т, 2005. - 234 с.

4. Харкема C., Берман А. Локомоторная тренировка: принципы и практика : учеб. пособие для врачей, методистов и инструкторов лечеб. фризкультуры [Электронный ресурс] / пер. с англ. Дмитрий Хавим. - Лос-Анджелес, 2002, 2006. - Режим доступа : http://beiych.ru/index. php?option $=$ com content $\&$ vicw $=$ articlc $\&$ id $=94: 2009-\mid$ 08-16-42\&catid=1 5:2009-10-02-07 29-26\&Uemid $=46$.

5. Юшковська О. Г. Фізична реабілітація хворих на ішемічну хворобу серця : монографія / О. Г. Юшковська. Одеса : Одес. держ. мед. ун-т, «Вид-во ВМВ», 2009. $224 \mathrm{c}$.

6. Юшковська О. Г. Шестихвилинний кроковий тест новий спосіб оцінки ефективності санаторно-курортної реабілітації хворих із серцево-судинною патологією / О. Г. Юшковська / / Мед. реабілітація, курортологія, фрізіотерапія. - 2007. - № 3. - C. 18-21.

7. Brooks D. ATS statement on six-minute walk test / D. Brooks, S. Solway, W. J. Gibbons // Am. J. Respir. Crit. Care Med. - 2003 . - Vol. 1. - P. 167.

8. Casanova C. The 6-min walk distance in healthy subjects: reference standards from seven countries / C. Casanova, B. R. Celli, P. Barria et al. // Eur. Respir. J. 2011. - Vol. 37. - P. 150-156.

9. Chau C. Early locomotor training with Clonidin in spinal cats / C. Chau, H. Barbeau, S. Rossignol / / J. Neurophysiol. 1998. - Vol. 79. - P. 392-409.

10. Duncan P. W. Body-Weight-Supported Treadmill Rehabilitation after Stroke / P. W. Duncan et al. / / N. Engl. J. Med . - 2011. - Vol. 364. - P. 226-236.

11. Gremeaux $V$. Determining the minimal clinically important difference for the six-minute walk test and the 200-meter fast-walk test during cardiac rehabilitation program in coronary artery disease patients after acute coronary syndrome / V. Gremeaux, O. Troisgros, S. Benaim // Arch. Phys. Med. Rehabil. - 2011. - Vol. 92(4). - P. 11-18.

12. MacKay-Lyons M. Central Pattern Generation of Locomotion: A Review of the Evidence / M. MacKayLyons // Phys. Ther. - 2002. - Vol. 82, N 1. - P. 69-83.

13. Scherer M. Gait rehabilitation with body weightsupported treadmill training for a blast injury survivor with traumatic brain injury / M. Scherer // Brain Inj. - 2007. Vol. 21. - P. 93-100.

14. Westlake K. Pilot study of Lokomat versus manualassisted treadmill training for locomotor recovery poststroke / K. Westlake, C. Patten // J. of NeuroEngineering and Rehabilitation. - 2009. - Vol. 6 - P. 18.

med_rehab@ukr.net

\section{References}

1. Vladimirov A. A., Vladimirov N. A., Ezhov I. (2011) The therapeutic nordic walking as a new modern form of physical therapy in sanatorium-resort conditions: method. recommendations. Kiev. (in Ukrainian)

2. Rumyantseva N. A. (2010) Comprehensive evaluation of pathological patterns of walking and rehabilitation programs of recovery in patients in acute period of cerebral stroke (PhD Thesis), Moscow (in Russian)

3. Sokolovskyy V. S., Romanova V. S., Yushkovska O. G. (2005) Therapeutic physical culture: Textbook [Remedial physical culture: textbook]. Odessa: Odessa state med. university (in Ukrainian)

4. Harkema S., Berman A. (2006) Locomotor training: principles and practice: teaching guide for physicians, methodologists and remedial physical culture instructors. Los Angeles, available at: http://beiych.ru/index.php?option=com content\&vicw $=$ articlc\&id=94:2009-I 1-09- 08-16-42\&catid=| 5:2009- 10-02-07 29-26\&Uemid $=46$. (in Russian)

5. Yushkovska O. G. (2009) Physical rehabilitation of patients with cardiac ischemia: monograph. Odessa: Odess. state med. university, "Publishing VMV» (in Ukrainian)

6. Yushkovska O. G. (2007) Six-minute walking test - a new method of evaluating the effectiveness of sanatorium rehabilitation of patients with cardiovascular pathology. Medical rehabilitation, balneology, physiotherapy, no 3, pp. 18-21. (in Ukrainian)

7. Brooks D., Solway S., Gibbons W. J. (2003) ATS statement on six-minute walk test. Am. J. Respir. Crit. Care Med., vol. 1, pp. 167.

8. Casanova C., Celli B. R., Barria P. (2011) The 6-min walk distance in healthy subjects: reference standards from seven countries. Eur. Respir. J., vol. 37, pp. 150-156.

9. Chau C., Barbeau H., Rossignol S. (1998) Early locomotor training with Clonidin in spinal cats. J. Neurophysiol., vol. 79, pp. 392-409.

10. Duncan P. W. (2011) Body-Weight-Supported Treadmill Rehabilitation after Stroke, N. Engl. J. Med., vol. 364, pp. 226-236.

11. Gremeaux V., Troisgros O., Benaim S. (2011) Determining the minimal clinically important difference for the sixminute walk test and the 200-meter fast-walk test during cardiac rehabilitation program in coronary artery disease patients after acute coronary syndrome. Arch. Phys. Med. Rehabil., vol. 92(4), pp. 11-18.

12. MacKay-Lyons M. (2002) Central Pattern Generation of Locomotion: A Review of the Evidence. Phys. Ther., vol. 82, pp. 69-83.

13. Scherer M. (2007) Gait rehabilitation with body weight-supported treadmill training for a blast injury survivor with traumatic brain injury. Brain Inj., vol. 21, pp. 93-100.

14. Westlake K., Patten C. (2009) Pilot study of Lokomat versus manual-assisted treadmill training for locomotor recovery post-stroke. J. of NeuroEngineering and Rehabilitation, vol. 6 , pp. 18 . 